\section{No sense and nonsense and noses}

\author{
Bryan D. Turner
}

The Doomsday Book of Animals: $A$ Natural History of Vanished Species. By David Day. Pp. 288. ISBN UK 0-85223-183-0; ISBN US 0-670-27987-0. (Ebury Press/Viking: 1981.) £14.95, $\$ 40$. After Man: A Zoology of the Future. By Dougal Dixon. Pp.124 ISBN UK 0-24611577-7; ISBNUS0-312-01163-6. (Granada/ St Martin’s Press: 1981.) £8.95, \$14.95. The Snouters: Form and Life of the Rhinogrades. By Harald Stümpke. Pp.118. ISBN pbk 0-226-77895-9. (Chicago University Press: 1981.) $\$ 4.95, £ 3.50$.

CATS, rats, mongooses and above all mankind have caused over 300 extinctions of vertebrate animals during the past 300 years. This rate is far greater than estimates of that of the dinosaurs' extinction at the end of the Age of the Reptiles in the late Cretaceous period. David Day's The Doomsday Book of Animals describes something of the biology, in many cases all the known biology, of these 300 vanished species and subspecies, and chronicles their final days. The style is factual and unemotional, but the book generates a great feeling of sadness as page after page records loss after loss. Those perceptive of the value of retaining the world's biological diversity will feel something of the corporate guilt that rests on Homo sapiens as the destroyer of that diversity.

By far the greatest losses have been suffered by island communities, with only 75 animal species or subspecies disappearing from the continental land masses including Australia. Of these, 16 are fish which died out as their small "aquatic islands" in North America were tampered with.

Whilst the introduction of cats, rats and mongooses, whether intended or accidental, has logically resulted in the extinction of many rare endemic island species and subspecies, particularly in the West Indies and the Mascarenes, in other instances it is almost inconceivable that a species could disappear because of the sheer size of its population. The extinction of the passenger pigeon is perhaps the most astounding case since it was probably the most abundant bird species in North America. Flock sizes of between one and two million birds were reported not 50 years before the very last passenger pigeon died in Cincinatti Zoo in 1914. They were hunted relentlessly for sport, food and quack medicine, and as the flocks became more scattered so the telegraph system was used to direct the hunters' efforts. Man the hunter does not operate as do other predatory species which switch to alternatives when favoured prey are uncommon thus allowing the preferred prey to recoup its losses. Rather, he develops tunnel vision and having formed a search image is unable to switch to another prey until forced to because that prey no longer exists. It is a characteristic of the examples in the Doomsday Book of Animals that as a species becomes rare through man's hunting pressure, so man's efforts against that species have tended to increase. Although there may be an awakening enlightenment that the world's diversity of species needs to be conserved, David Day's beautifully illustrated and poignant book ends pessimistically by reminding its readers that there are currently over 400 critically endangered species, many of which will become extinct in the near future.

When human beings themselves become extinct and take with them many of the groups of animals we know today, new life forms will evolve to fill the resulting ecological lacunae. This is the basis of Dougal Dixon's look into the future, 50 million years hence. Although AfterMan is fun, and displays some imagination, the biological framework within which it purports to operate is clearly little understood. In many cases the futuristic species just could not follow the lifestyle attributed to them. What happens to the leaping devil (Daemonops rotundus), a sort of carnivorous jerboa, after it has sunk its needle teeth into a large lizard? It has neither the apparatus nor the capacity to do much else unless it swallows the lizard whole and becomes the rolling devil. How does the gigantelope (Megalodorcas giganteus) actually eat the bulbs and roots it grubs up with its splendid horns, which extend in front and below the animal's muzzle and prevent its getting near the ground? The

\section{Bryan D. Turner is a Lecturer in Zoology at} King's College, University of London.

Whereas After Man tends to be conserforms, Harald Stümpke's (alias Gerolf Steiner) zoological fantasy is highly inventive. Absent from the bookshops for the past ten years, the reprinting of The Snouters has been long overdue. It is an account of the adaptive radiation of a small group of insectivorous mammals which are characterized by the extensive development of the nose or nasarium. Among the 189 species in the order Rhinogradentia the nasarium is variously used - as a temporary support while the legs serve for food processing; as an adhesive organ in the sedentary species; as a jumping organ in the hopsorrhines; and in the polyrrhines it becomes sub-divided into foot or tentacle structures. Throughout this bizarre but fascinating account the form and function are minutely examined in true Germanic taxonomic style.

Such realism will endear The Snouters to those with a zoological background but students should beware the rhinogrades, they are prime spoof material for inclusion in vertebrate courses. However it may be amusing to see whether straight faces can be maintained when the feeding habits of Nasobema lyricum are explained. This beast feeds on fruits which it reaches by, to put it politely, passing wind into its inflatable tail thus momentarily producing a long rigid appendage with a grasping tip. $\square$ book is shot through with biological anomalies and lacks credibility despite the introduction by Desmond Morris, who should have known better than to attribute the book with "real scientific value". vative in its conception of alternative life

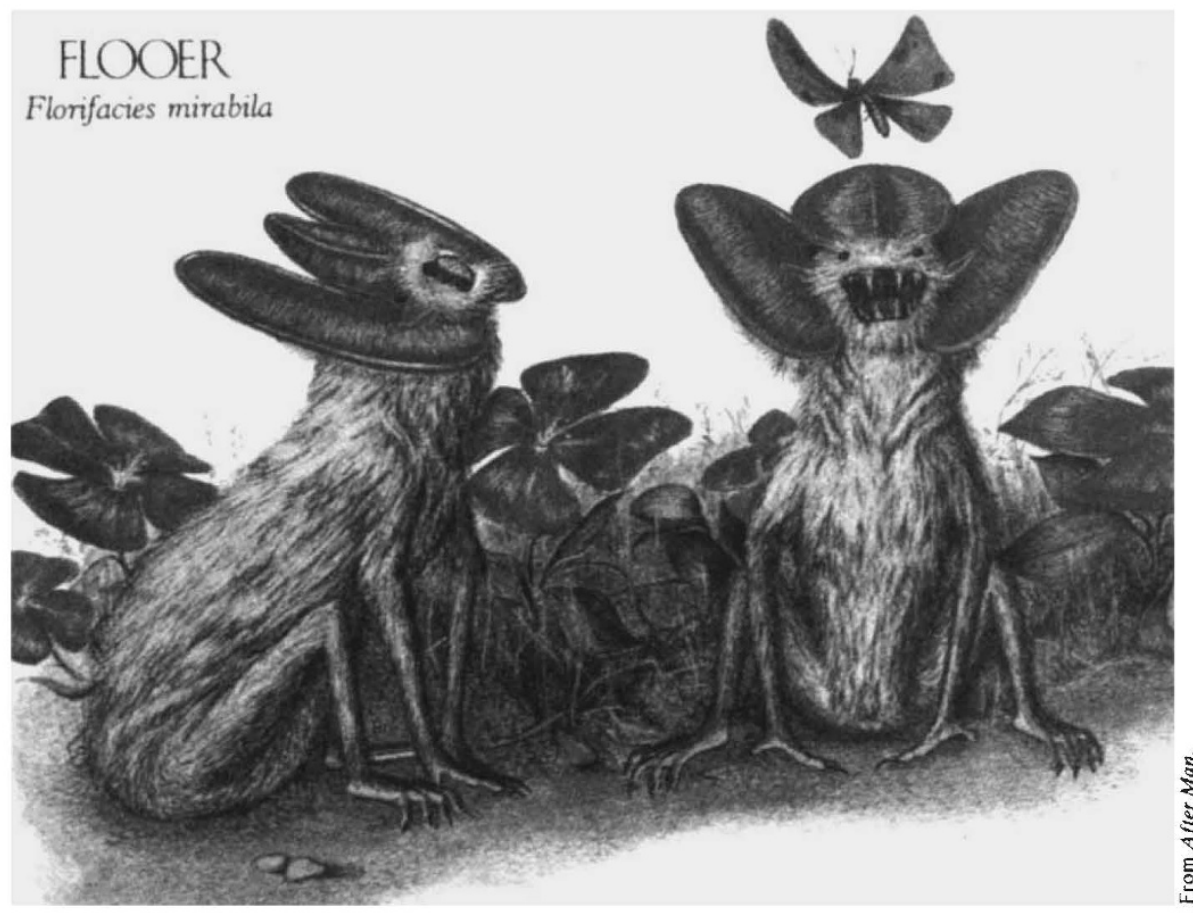

The insectivorous flooer (Florifacies mirabila). The animal has glands around its mouth which produce a sweet-smelling secretion and attract the flooer's prey. 